\title{
On the Establishment and Application of Broad Prohibition of Repeated Suits in Chinese Law - With "The Requests in the Latter Lawsuit Essentially Deny the Judgement in the Former Lawsuit" as the Object
}

\author{
Jiazhen Guo ${ }^{1}$ \\ ${ }^{1}$ Law School of Beijing Normal University, Beijing, China \\ Correspondence: Jiazhen Guo, Law School of Beijing Normal University, No. 19, XinJieKouWai St., HaiDian \\ District, Beijing 100875, China. Tel: 86-187-3788-3815. E-mail: 605638892@qq.com
}

Received: September 25, 2019

Accepted: November 22, 2019

Online Published: November 28, 2019

doi:10.5539/jpl.v12n4p79

URL: https://doi.org/10.5539/jpl.v12n4p79

\begin{abstract}
Article 247 of the Interpretation of Civil Procedure Law stipulates the prohibition of repeated suits, but it only refers to the narrow prohibition of repeated suits. Its identification elements are "the same parties, the same subject matter of claims and the same requests of the lawsuit". However, there is a widespread phenomenon in judicial practice that the court rejects the latter lawsuit by using the element "the requests in the latter lawsuit essentially deny the judgement in the former lawsuit". Through the analysis of legal hermeneutics, this element can be used when the former lawsuit is in proceeding and should be understood as "if the latter lawsuit is made, the judgement of latter lawsuit may deny the judgement of the former lawsuit". Therefore, Article 247 of the Interpretation of Civil Procedure Law establishes the broad prohibition of repeated suits. The identification element of broad prohibition of repeated suits should be that the main points of contention of the two lawsuits are the same. With regard to the treatment of the broad repeated suits, the latter court can directly reject it, but should fulfill the obligation of "addition of lawsuit, alteration of lawsuit or counterclaim can be put forward in the former lawsuit" to the parties.
\end{abstract}

Keywords: broad prohibition of repeated suits, main points of contention, compulsory counterclaim, clarify obligations

\section{Introduction}

Article 247 of the Interpretation of Civil Procedure Law stipulates the elements of repeated suits that the same parties, the same subject matter of claims, the same lawsuit requests or the requests in the latter lawsuit essentially deny the judgement in the former lawsuit. With regard to the element that " the requests in the latter lawsuit essentially deny the judgement in the former lawsuit", the theorists generally hold that it mainly refers to the negative effect of the principle of res judicata and it is only applicable to the stage where the judgment has taken effect. However, it is common to contradict this theory in practice and a considerable number of courts apply this element when the former lawsuit is in proceeding. Therefore, it is necessary to clarify the application and meanings of the important element that "the requests in the latter lawsuit essentially deny the judgement in the former lawsuit".

Case 1: In the former lawsuit, $\mathrm{A}$ requested $\mathrm{B}$ and $\mathrm{C}$ to repay the principal and interest of the loan and $\mathrm{D}$ to assume joint and several liability for the debt. The court of first instance ruled in favor of the claim. D refused to accept it and appealed to the court of second instance. During the second instance of the case, D put forward a separate lawsuit to revoke the guarantee contract with B and C. Both the court of first instance and the court of second instance of the case considered that $\mathrm{D}$ put forward a contradictory lawsuit to the court when the former lawsuit is in proceeding, which negated the judgment of the former lawsuit. (2016Yue 51Min Zhong No.67.)

Case 2: In the former lawsuit, A requested the confirmation that the contract signed with $\mathrm{B}$ was terminated on August 8, 2008, and requested $\mathrm{B}$ to refund the deposit and down payment for the house purchase and compensate for the corresponding losses. The case was currently being tried in the first instance, and B took A as the defendant, puting forward a separate lawsuit and asking to confirm the invalidity of the above-mentioned 
contract and compensate for the rental losses caused by the invalidity of the contract. The court of second instance held that the requests of former lawsuit and latter lawsuit were contrary and the latter requests essentially denied the judgment of the former lawsuit, so it was a repeated suit and should be rejected. (2015 No.4855 of No.1 Middle School People's Court.)

In case 1, the former is a lawsuit of performance, and the latter lawsuit is a lawsuit for revocation of contract. The former lawsuit is being tried and there is no judgment result yet, but the latter court rejected the latter lawsuit by using the element of "the requests in the latter lawsuit essentially deny the judgement in the former lawsuit". In case 2, the former lawsuit and the latter lawsuit are essentially both the lawsuit of performance, and the confirmation request is only a prerequisite legal relationship for the payment requests. Although the two lawsuits have some connections in the pre-requisite legal relationship, they are different subject matter of claims, and the latter lawsuit does not satisfy the elements of Article 247 of the Interpretation of Civil Procedure Law. Knowing that the former lawsuit was being tried in the first instance, the latter court still rejected the latter lawsuit by using the element that " the requests in the latter lawsuit essentially deny the judgement in the former lawsuit", which obviously violated the basic legal principle of civil litigation.

There are many cases like this in practice, and quite a few judges apply the element to the latter lawsuit when the former lawsuit is in proceeding. Therefore, the practice circles have not formed a consensus on the application stage of this element. Moreover, some scholars in the theoretical circles also believe that this element can be applied when the former lawsuit is in proceeding. This leads to the thesis of this article - how to explain and apply the element "the requests in the latter lawsuit essentially deny the judgement in the former lawsuit". That is, this article try to figure out whether this element can be applied when the former lawsuit is in proceeding, and if applied, what are the specific application situations and elements? The article intends to discuss these issues in order to clarify the application of the elements of repeated suits.

\section{The Analysis of Legal Hermeneutics on the Element "The Requests in the Latter Lawsuit Essentially Deny the Judgement in the Former Lawsuit"}

\subsection{Does the Element can Be Applied When The Former Lawsuit Is in Proceeding?}

From the perspective of literal interpretation, because the legal text uses the word "judgment", and influenced by this word, scholars will naturally assume that the prerequisite for the use of this element is that the judgment of former lawsuit has taken effect. However, there are two questions about this interpretation: first, it is one-sided because of not puting this element in the whole Article 247 of the Interpretation of Civil Procedure Law. Second, it conflicts with the original legislative intent of the Supreme Court, limiting the purpose of setting this element. Due to the inadequacy of literal interpretation, other interpretation methods can be adopted to supplement the original intention of the legal norms.

Firstly, from the perspective of system interpretation, as some scholars have said, Chinese definition of repeated suits is to mix the repeated suits in which the former lawsuit is in proceeding with the repeated suits in which the former lawsuit has taken effect. Therefore, when explaining the important element that "the requests in the latter lawsuit essentially deny the judgement in the former lawsuit", we should be based on the above understanding and put it in the context of the whole clause to understand, instead of only drawing a conclusion from its literal meaning that the element is only applicable to the stage where the former lawsuit has taken effect. From the arrangement of Article 247 of the Interpretation of Civil Procedure Law, it can be seen that whether the former lawsuit is in proceeding or the judgment of former lawsuit has taken effect, the elements for distinguishing the latter lawsuit as a repeated suit are the same parties, such as the same subject matter of claims, the same requests of lawsuit or the requests in the latter lawsuit essentially denying the judgement in the former lawsuit. Therefore, judging from the overall framework of the clause, the judicial interpretation does not clearly stipulate that "the requests in the latter lawsuit essentially deny the judgement in the former lawsuit" is only used in the stage where the judgment of former lawsuit has taken effect.

Secondly, from the perspective of purpose interpretation, we can probe the original legislative intent of this element from the interpretation of the Supreme Court. As a matter of fact, regarding the definition of repeated suits, Taiwan and Japan are gradually getting rid of the shackles of subject matter of claims and surface meaning and adopting purposive interpretation theory according to the function of repeated suits. Therefore, when we seek the interpretation and application of the element "the requests in the latter lawsuit essentially deny the judgement in the former lawsuit", naturally we cannot ignore the original setting purpose of this clause. The Supreme Court holds that the meaning of "the requests in the latter lawsuit essentially deny the judgement in the former lawsuit" is that the latter lawsuit puts forward an opposite request and cites two examples as auxiliary explanations. One, A sued B for payment according to the legal relationship, while B sues A to confirm that the 
legal relationship is invalid. Two, A sues B to confirm that the legal relationship is invalid, while B sues A to confirm that the legal relationship is valid. The above interpretation obviously does not refer to the situation where the judgement of former lawsuit has already taken effect. The three interpretations do not specify the judgment of former lawsuit and only focus on the negative relationship between the former requests and the latter requests. This kind of comparison can only occur when the two lawsuits are in proceeding at the same time. Besides, there will be a logical contradiction if the interpretation is placed in the situation where the judgement of former lawsuit has taken effect. The reason is that the effective judgment of the former lawsuit only blocks the requests that are contrary to its result, not all the requests that are contrary to the requests of former lawsuit. For example, if the former lawsuit failed, the defendant's requests contrary to the former lawsuit will not negate the judgment of the former lawsuit, so naturally it will not be blocked. Obviously, the interpretation of Supreme Court and the examples cited are all aimed at the situation where the former lawsuit is in proceeding. As for some scholars' opinions that the interpretation of Supreme Court is actually a misunderstanding of the res judicata contained in this element (Yuan, 2017, p.31), the author thinks that it is meaningless to interpret the res judicata of this clause specially. Beyond that, even if the Supreme Court wants to interpret the res judicata, it will not appear the basic fallacy that "the meaning of this element is that the latter lawsuit puts forward an opposite request", the Supreme Court will express it as "the latter lawsuit puts forward a request that contraries to the judgment of the former lawsuit". Therefore, we can infer that the reason why the Supreme Court pays attention to the negative relationship between the former requests and the latter requests is actually to emphasize the application where two lawsuits are in proceeding. The purpose is to make this element not only exert the negative effect of res judicata inherent in the effective judgment, but also regulate the latter lawsuit when the former lawsuit is in proceeding.

Therefore, whether from the perspective of system interpretation or purpose interpretation, the element that "the requests in the latter lawsuit essentially deny the judgement in the former lawsuit" is not only applicable to the stage where the judgement of former lawsuit has taken effect, but also applicable to the stage where the former lawsuit is in proceeding. However, the key issue is to clarify the apparent logical contradiction in the regulation between the words "in proceeding" and "judgement".

\subsection{The Meaning of this Element When the Former Lawsuit Is in Proceeding}

In order to find out the meaning of the element that "the requests in the latter lawsuit essentially deny the judgement in the former lawsuit" when the former lawsuit is in proceeding, we still need to go back to the interpretation of Supreme Court about this element. First, "the requests in the latter lawsuit essentially deny the judgement in the former lawsuit" mainly refers to the situation where the latter lawsuit puts forward an opposite request, and this interpretation is to prevent two opposing requests from being tried at the same time, resulting in the incompatible contradictory judgments. Second, A sues B for payment according to the legal relationship, while B sues A to confirm that the legal relationship is invalid. Because the lawsuit of payment includes the lawsuit of confirmation, once the lawsuit of payment is confirmed, its res judicata will also reach the lawsuit of confirmation. Therefore, if the defendant is allowed to put forward the lawsuit of negative confirmation when the lawsuit of payment is in proceeding, the judgment of the latter lawsuit may negate the judgment of the former lawsuit, resulting in the conflict of res judicata. Third, A sues B to confirm that the legal relationship is invalid, while B sues A to confirm that the legal relationship is valid. This case is similar to the interpretation one, so the purpose is the same. As a result, the meaning of "the requests in the latter lawsuit essentially deny the judgement in the former lawsuit" is also expanded and interpreted as "if the latter lawsuit is conducted, the judgment of the latter lawsuit may negate the judgment of the former lawsuit".

In this sense, "the requests in the latter lawsuit essentially deny the judgement in the former lawsuit" has also established the broad prohibition of repeated suits. There are two types of prohibition of repeated suits when the former lawsuit is in proceeding: the first is the narrow prohibition of repeated suits, namely the parties put forward the same requests, for which the latter court should directly decide not to accept the lawsuit, and the already accepted ruling rejects the lawsuit. Reflected in the legal norms of our country, it is the first half of the third paragraph of Article 247 of the Interpretation of Civil Procedure Law. The second is the broad prohibition of repeated suits that the parties put forward different requests to the court that may result in the contradictory judgments. (Chen, 2016, p.186)

In the context of "the judgment of the former lawsuit may negate the judgment of the latter lawsuit", although the latter request is not the same as the former request, it is easy to cause contradictory judgment, thus conforming to the concept of broad prohibition of repeated suits. Japan and Taiwan have different ways of dealing with the broad prohibition of repeated suits. The Japanese academic circles do not advocate rejecting the lawsuit on the ground that the lawsuit is not unlawful, but they prohibit the parties from putting forward a 
separate lawsuit and carry out compulsory merger (addition of lawsuit, alteration of lawsuit or counterclaim). However, Taiwanese academic circles advocate directly rejecting separate lawsuit under the condition that the procedural rights of the parties are fully protected.

In contrast, the author is more in favor of the latter's handling method, because this method can prevent the parties from putting forward a separate lawsuit to the greatest extent through the judge's clarification in advance, thus preventing the occurrence of contradictory judgments and the problem of diseconomy of lawsuit, realizing the goal of one-time dispute resolution, and at the same time protecting the rights and interests of the parties. However, Japanese method is actually based on that there is no means to compel the parties to carry out compulsory merger (addition of lawsuit, alteration of lawsuit or counterclaim) in advance. Therefore, the only way that Japanese law can take is that the court needs to reject the lawsuit when the parties put forward a separate lawsuit. Meanwhile, the parties must abandon the existing procedures and put forward an addition of lawsuit, alteration of lawsuit or counterclaim again. Such a practice raise the suspicion of increasing the time and cost of the parties and make them lose the limitation period. The establishment of broad prohibition of repeated suits can not only play the general function of prohibition of repeated suits to avoid the vexation of defendants responding to lawsuits, the uneconomical results caused by repeated court hearings, and to prevent contradictory judgments, but also have the function of forcing the parties to use the former procedure for putting forward an addition of lawsuit, alteration of lawsuit or counterclaim. With this function, we can give full play to the benefits brought about by the compulsory merger, such as expanding the litigation system to resolve disputes, etc. Even if the parties do not make full use of this opportunity and choose to start the lawsuit after the confirmation of the former lawsuit, the judgment of the former lawsuit can be used as a reference or binding force for the court of the latter lawsuit, thus promoting the proper settlement of disputes. (Chen, 2012, p.38)

\section{Identification Elements of Broad Prohibition of Repeated Suits}

\subsection{Identification Elements in Comparative Law}

Japanese and Taiwanese theorists believe that, unlike the narrow prohibition of repeated suits focus on the elements of lawsuits, the broad prohibition of repeated suits focus on the institutional interest of prohibition of repeated suits. That is, if there are risks of repeated hearing and contradictory judgments when two lawsuits are conducted at the same time, even if the two lawsuits have different subject matter of claims or different forms of rights protection, they can only be handled by putting forward an addition of lawsuit, alteration of lawsuit or counterclaim in the former lawsuit, and cannot be prosecuted separately. According to the intention of system, the identification elements of broad prohibition of repeated suits can be divided into two types: the same request basis and the same main points of contention. The so-called request basis identity refers to the fact that the main points of contention between the former lawsuit and the latter lawsuit are the same and the lawsuit materials are the same. The same main points of contention refer to the fact that the matters are disputed both as the main points of contention in the former lawsuit and as the main points of contention in the latter lawsuit. The former emphasizes "the repetition of legal proceedings", while the latter focuses on "the effectiveness of issue". Although the two types of identification elements have different focuses, in conclusion, the elements of "the same request basis" and "the main points of contention" are almost the same.

\subsection{Chinese Identification Elements}

Through the investigation of comparative law, it can be seen that the elements of broad prohibition of repeated suits are mainly the same parties and the same main points of contention. However, since Article 247 of the Interpretation of Civil Procedure Law of our country has clearly stipulated the elements of repeated suits, it is necessary to set the elements of repeated suits in combination with the legal norms of our country.

Firstly, the parties of the former lawsuit and the latter lawsuit are the same, about which there is not much dispute in the academic circles. Apart from the situation that the parties of the former lawsuit and the latter lawsuit are exactly the same, the situation where the parties exchange the plaintiff and the defendant positions in the former and latter lawsuit also belongs to "the same parties" situation. In addition, in the case where the scope of the parties involved in the former lawsuit and latter lawsuit is not completely coincident, as long as the number of parties involved in the latter lawsuit is less than that of the former lawsuit, in principle, it should also be regarded as "the same parties". Besides, if a person subjects to the subjective scope of res judicata puts forward a separate lawsuit, it also meets the element that "the parties of the former lawsuit and the latter lawsuit are the same". (Wang \& Chen, 2015, p.12)

Secondly, the subject matter of claims of the former lawsuit and the latter lawsuit are the same. In fact, according to the practice of comparative law, under the broad prohibition of repeated suits, it is not necessary to consider whether the subject matter of claims is the same. Therefore, in order to reduce the impact of this element on the 
identification of broad prohibition of repeated suits, this element under broad prohibition of repeated suits is not required.

Thirdly, the judgment of the latter lawsuit may negate the judgment of the former lawsuit. This element is the substantive element for determining the broad prohibition of repeated suits. The question is how to define this element. It first requires clarifying the meaning of contradictory judgments. Contradictory judgments are divided into conflicting judgments in terms of res judicata and inconsistent judgments in terms of substantive law order. Conflicting judgments in terms of res judicata refer to judgments based on formal criteria, namely the two lawsuits are contradictory in the main text of the judgment, and their elements should be the same parties and requests. This type of lawsuits should be regulated by the narrow prohibition of repeated lawsuits. Inconsistent judgments in terms of substantive law order mean that the two lawsuits do not seem to conflict in the main text of the judgment, but cannot coexist in the substantive law order. For example, the plaintiff puts forward a lawsuit to revoke the contract, and in the trial of the case, the defendant puts forward another lawsuit to request to perform corresponding obligations according to the contract. Only from the referee's text, the res judicata of the two lawsuits does not conflict. However, from the point of view of substantive law order, the main common point of contention between the two lawsuits is whether the legal relationship is legal and effective. If the courts make different judgements on this point of contention, it will produce legal effects that cannot coexist. This type of lawsuits should be regulated by the broad prohibition of repeated lawsuits, and its identification elements should be the same parties and main points of contention.

According to the above analysis ,the author believes that the identification elements of the broad prohibition of repeated suits in our country should be the same parties, while the important element "the requests in the latter lawsuit essentially deny the judgement in the former lawsuit" should be understood as "the main points of contention are the same."

\section{The Types of Broad Prohibition of Repeated Suits}

According to the elements of the broad prohibition of repeated suits, this kind

of lawsuits mainly includes the following types:

\subsection{The Latter Requests Directly Deny the Former Requests}

When the latter requests directly deny the former requests and the latter parties do not put forward different points of contention, as the judgment is made according to the requests. As long as the latter requests conflict with the former requests, a contradictory judgment may occur. There are two main cases as follows:

The first type is that both the plaintiff and the defendant put forward positive confirmation lawsuits on the same subject matter of claims. For example, the plaintiff puts forward a lawsuit to confirm his ownership of something, while the defendant also puts forward another lawsuit to confirm his ownership. The main points of contention between the two lawsuits are the same, and there is only one ownership on one subject matter, so if the two lawsuits are tried at the same time, it is likely to result in the contradictory judgments. The court should reject the latter lawsuit in this case. However, in view of the fact that the former court will not try whether the defendant has the ownership, the defendant has the interest of lawsuit suing for confirmation, so the requests should be made by putting forward a counterclaim in the former lawsuit.

The other type is the coexistence of positive confirmation lawsuit and negative confirmation lawsuit. For example, cited by the Supreme Court, A sues B to confirm that the legal relationship is invalid, while B sues A to confirm that the legal relationship is valid. In this case, the latter request directly opposes the former requests, and the two lawsuits have the same main points. If the two lawsuits are tried at the same time, the judgment of the latter lawsuit will most likely negate the judgment of the former lawsuit, resulting in the contradictory judgments. Therefore, the court should recognize the latter lawsuit put forward by B as a repeated suit and reject it. At the same time, B can not put forward a counterclaim on his request, because the plaintiff of the counterclaim and the defendant of former lawsuit have the same requests and the request of the defendant of former lawsuit has been protected in the former lawsuit, the counterclaim does not have the interest of lawsuit. (Duan, 2014, p.78)

\subsection{The Main Points of Contention between the Former Lawsuit and the Latter Lawsuit Are the Same}

In addition to the type that the latter requests directly deny the former requests, the situation that the latter requests form a contradictory judgments phenomenon by denying the precondition of the former requests is also consistent with the broad prohibition of repeated suits. The main types are as follows:

The first situation is that the former is a lawsuit for negative confirmation put forward by the plaintiff and the 
latter is a lawsuit of performance put forward by the defendant. Because the premise for the establishment of the latter lawsuit is the effective existence of legal relationship, whether the legal relationship exists effectively has become the main point of contention between the two lawsuits. Considering this, the court should also rule to reject the latter lawsuit. However, in view of the fact that the latter requests do have the interest of lawsuit, the requests should be made in the form of a counterclaim.

The second situation is that the former is a lawsuit for revocation of contract and the latter is a lawsuit of performance. The purpose of the former lawsuit is to invalidate the legal relationship. If the latter lawsuit makes a request for payment on the premise--the effective existence of the legal relationship, although there is no direct contradiction between the two parties in terms of requests, it is easy to form contradictory judgments that cannot coexist in the substantive law order because of the contention that "whether the legal relationship is effective". Therefore, according to the principle of broad prohibition of repeated suits, the court should rule to reject the latter lawsuit and the requests should be made in the form of a counterclaim.

The third situation is that the former is a lawsuit of performance and the latter is a lawsuit for revocation of contract. The situation has its particularity due to the nature of the revocation right. If the contract has serious misunderstanding and other revocable reasons, the parties can naturally put forward the lawsuit for revocation of the contract to invalidate the legal relationship. However, the question is that if the former lawsuit is in proceeding, can the defendant put forward a separate lawsuit for revocation of contract? The author thinks that it is negative. When the plaintiff puts forward a lawsuit to request the payment based on the effective existence of a certain contract legal relationship, and the defendant puts forward another lawsuit to revoke this legal relationship, although the latter lawsuit does not directly deny the requests of the former lawsuit, the court should also rule to reject the latter lawsuit because the latter lawsuit's revocation directly points to the prerequisite of the former lawsuit (the basic legal relationship of the payment lawsuit), and different judicial organs may form different judgments on this prerequisite, and thus it is easy to result in the consequence that the judgment of the latter lawsuit denies the former lawsuit. However, because the defendant has the interest of lawsuit to revoke this legal relationship, the requests should be made in the form of a counterclaim.

The fourth situation is that the defendant wishes to put forward a separate lawsuit on his right of defense in the former lawsuit. For example, the plaintiff sued to return the house according to the right of ownership, and the defendant argued that he enjoyed the house based on the lease right and have the right to possess it. During the trial of the case, the defendant puts forward a separate lawsuit to confirm that he has the right of lease about the property in dispute. Only from the point of view of the former requests and the latter requests, the two lawsuits do not seem to conflict. However, the main points of contention of the former lawsuit and the latter lawsuit are the same, that is, "whether the defendant enjoys the lease right", and the judgment of the court on this point of contention will directly affect whether the former plaintiff can realize his rights. Therefore, if the defendant is allowed to put forward a separate lawsuit for lease right, the court will conduct two substantive trials on this dispute, which not only wastes judicial resources, but also easily forms two contradictory judgments. Therefore, if the defendant wants to put forward a lawsuit on their right to defense, they should do so in the form of a counterclaim instead of putting forward a separate lawsuit.

\section{The Treatment and Guarantee of Broad Prohibition of Repeated Suits}

\subsection{Japanese Treatment}

Japanese scholars suggest that the latter court should apply the stipulation of "forbidding separate prosecution and compulsory merger" to the broad repeated suits. In other words, the latter court will not reject the lawsuit because the lawsuit is unlawful, but will merge the former lawsuit with the latter lawsuit according to its authority, thus the parties will be induced to put forward a "Addition of lawsuit or alteration of lawsuit or counterclaim". However, the defects of this method is: firstly, if the courts of the two lawsuits are different, the two lawsuits cannot be merged directly, but the latter lawsuit should be transferred by using Article 17 of the Japanese Civil Procedure Law to create a state where the two lawsuits belong to one court at the same time. However, the premise of this approach is that the transferred court must have jurisdiction over the latter lawsuit. However, this condition can not always be satisfied, so "forbidding separate prosecution and compulsory merger" is not always feasible. Secondly, whether the case is merged or transferred, it is the object of the judge's discretion in the current law, so there is no legal guarantee for the element that "the court must merge or transfer".

\subsection{Taiwanese Treatment}

Taiwanese scholars believe that although the subject matter of claims of the two lawsuits are not the same, if the court has fulfilled the corresponding clarifying obligation in the former lawsuit and can expect the defendant to 
put forward a counterclaim in the former lawsuit and the defendant still wants to put forward another lawsuit at this time, it can be considered that the defendant has not impartially exercised the lawsuit, and the court should rule to reject the lawsuit. As for the substantive or procedural interests of the parties caused by the rejection of the lawsuit, which should be taken by the parties themselves. (Xu, 2003, p.243)

For example, the plaintiff claimed to return the special property according to the right of returning ownership petition and the defendant defended that he had the right to lease the property. According to Item 2 of Article 199-1 of Taiwan's Civil Procedure Law, the judge should clarify to the defendant that he can put forward a counterclaim about the defense right. If the defendant refuses to put forward a counterclaim and puts forward another lawsuit under the circumstances clearly clarified by the court, it should be considered that the latter lawsuit has no interest of lawsuit and should be rejected. This restriction does not affect the opportunity for the parties to take advantage of the litigation system and hinder the parties' freedom of litigation. The reason is that if the defendant wants to confirm the existence of his defense right, he can put forward a counterclaim in the former lawsuit procedure, which does not reduce the litigation opportunity and rights of the defendant. Therefore, it cannot be said that the prohibition of another prosecution violates his litigation right. In addition, this practice does not deprive the parties of the procedural option, because it does not force the defendant to put forward a counterclaim. In other words, the court makes a corresponding clarification, providing more information to the defendant so that the defendant can decide whether to use the former lawsuit procedure to put forward a lawsuit after considering the substantive interests and procedural interests. This does not violate the principle of disposition right, and still respects the parties' procedural option. The author believes that this practice is conducive to the settlement of disputes in a procedure, and better safeguard the parties' litigation rights and procedural options. However, the remaining question is whether it is still justified to apply the principle of broad prohibition of repeated suits when the court failed to fully fulfill its obligation of clarification. And if the defendant is not fit to put forward a counterclaim in the former suit, should the court reject the latter lawsuit altogether?

\subsection{The Way Our Country Should Deal with It}

our country seldom mentions the broad prohibition of repeated suits in theory, and the legislation doesn't directly involve it. However, the current legal norms at least provide the following different solutions to this kind of substantive and repeated suits: the first is to reject the latter lawsuit according to the element "the requests in the latter lawsuit essentially deny the judgement in the former lawsuit". The second is to transfer the case to the former court to form a compulsory merger according to Article 2 of the Supreme People's Court's "Several Provisions on Strict Implementation of the Civil Procedure Law of the People's Republic of China in Economic Trials". The third is that for some cases, the court can suspend the proceedings according to the provisions of Article 150 of the Civil Procedure Law. For these three methods, the first method of direct rejection is similar to the method advocated by Taiwanese academic circles. Although this method can avoid contradictory judgments to the greatest extent, it is easy to infringe the procedural rights of the parties. The second method of transfer for compulsory merger is similar to the method advocated by the Japanese academic circles, but it is easily questioned by jurisdictional issues and the absence of compulsory measures. While the defect of suspending the lawsuit is that if the former lawsuit is illegal, the trial result can no longer be used, and the judgement of the latter lawsuit can not quote the testimony of witnesses in the former lawsuit, which is not conducive to the economy and efficiency of the lawsuit. (Zhao, 2017, p. 113)

Compared with the above treatments, the author suggests the first method while ensuring the rights of the parties concerned. The advantages of this approach are as follows: firstly, it can avoid the occurrence of contradictory judgments to the greatest extent and the uneconomical result of repeated trial by the court, and achieve the goal of one-time dispute resolution. Secondly, it can effectively avoid the defects of the two methods of compulsory merger and suspension of trial. Compulsory addition of lawsuit, compulsory alteration of lawsuit or compulsory counterclaim is more concise than compulsory merger, which can save the step of reporting to the common superior court for designation of jurisdiction due to jurisdictional disputes between different courts. In addition, the compulsory addition of lawsuit, compulsory alteration of lawsuit or compulsory counterclaim does not need to wait for other lawsuits to be concluded and is more centralized and efficient. Thirdly, the unification of the application of legal norms can be maintained, because Article 247 of the Interpretation of Civil Procedure Law only provides one method that the court does not accept the case or rule to reject the case after accepting it, so rejecting lawsuit is consistent with this legal norm.

However, this treatment requires the perfection of the following provisions: Firstly, the conditions for the parties to alter requests or put forward counterclaims should be relaxed. In our country, the conditions for altering requests and putting forward counterclaims are not clear enough, and in the second instance procedure, the 
parties are not allowed to alter their requests. Adding requests or putting forward counterclaims also require the consent of the opposite parties or a successful mediation. Otherwise, the court needs to inform the parties of putting forward another lawsuit. Under these circumstances, the parties concerned must still start a separate lawsuit. However, if the former court directly rejected the lawsuit of the parties before and the parties put forward another lawsuit at this time, the parties would face the dilemma of no remedy. In this regard, the conditions for the parties to alter requests and put forward counterclaims should be relaxed, and the parties can put forward counterclaims and make changes in the lawsuit as long as the basic facts of the two claims are the same or the main points of contention are the same, whether in the first or second instance. Only in this way can the party's lawsuit be rejected without infringing on his litigation rights. Secondly, it is necessary to strengthen the court's clarifying obligation in the future. In order to avoid increasing the burden on the parties, urge the parties to add or alter timely their requests or put forward counterclaims in the former lawsuit, judges should strengthen their clarification of the addition of lawsuit, alteration of lawsuit and counterclaims.

\section{References}

Beijing No.1 Intermediate People's Court. (2015). No.4855 of No.1 Middle School People's Court.

Chaozhou City Intermediate People's Court Civil Decision. (2016). Yue 51Min Zhong No.67.

Chen, H. P. (2016). A New Paradigm of the Theory of the Subject Matter of Claims. Chinese journal of law, (4), 186.

Chen, W. Y. (2012). The concept of subject matter of claims and the principle of prohibition of repeated suits-starting from the reflection on the concept of subject matter of claims in german law. Political university law review, (127), 38.

Duan, W. B. (2014). Analyzing Japan's Non Bis in Idem and Its Types. Journal of Comparative Law, (5), 78.

Wang, Y. X., \& Chen, X. T. (2015). The Impact of former lawsuit Judgment on latter lawsuit: An Analysis of Articles 93 and 247 of Interpretation of Civil Procedure Law. Journal of East China University of Political Science and Law, (6), 12.

Xu, S. H. (2003). Prohibition principle of repeated suits and objective scope of res judicata.in Xu Shihuan, procedural guarantee and obligation of clarification. Taiwan: Xuelin Cultural Enterprise company.

Yuan, L. (2017). Repetitive Suits from the Perspective of "Claims in the Latter Lawsuit Deny the Judgment in the Former Lawsuit". Journal of Southwest University of Political Science \& Law, (1), 31.

Zhao, X. J. (2017). Research on the Procedural Value of Declaratory Lawsuit. The Jurist, (6), 113.

\section{Copyrights}

Copyright for this article is retained by the author(s), with first publication rights granted to the journal.

This is an open-access article distributed under the terms and conditions of the Creative Commons Attribution license (http://creativecommons.org/licenses/by/4.0/). 